\title{
Cut Throat Injuries-A Retrospective Study at a Tertiary Referral Hospital
}

\author{
Suman Arasikere Panchappa*, Dhinakaran Natarajan, Thangaraj Karuppasamy, \\ Alaguvadivel Jeyabalan, Radhakrishnan Kailasam Ramamoorthy, \\ Sivasubramanian Thirani, Rajaganesh Kutuva Swamirao \\ Department of ENT, Madurai Medical College, Madurai, India \\ Email: ${ }^{\text {rajsuman91@yahoo.com }}$
}

Received 22 August 2014; revised 20 September 2014; accepted 19 October 2014

Copyright (C) 2014 by authors and Scientific Research Publishing Inc.

This work is licensed under the Creative Commons Attribution International License (CC BY). http://creativecommons.org/licenses/by/4.0/

cC) (7) Open Access

\begin{abstract}
Objective: To analyze the socio demographic pattern, sex and age ratio, common causes, the most common site and extent of the injury in the patients with cut throat injury at our hospital. To compare the same with previous similar studies conducted at other centers in different parts of the world. Setting: Department of ENT, Government Rajaji Hospital, Madurai, India from January 2013 to June 2014. Methods: A total of 51 cases of cut throat injury were included in the study. Separate proforma was prepared to collect the patients' data. Structured questionnaire was offered. Results: 51 cases of cut throat injury patients were included in the study. Age varied from 4 years to 80 years. Out of 51 cases, there were 43 males, 7 females and one male child. Male to female ratio was 6.2:1. All the patients were belonging to lower socioeconomic status (Kuppusamy class 5). Amongst them 26 cases $(50.98 \%)$ were due to homicidal attack; 13 cases $(25.49 \%)$ due to suicidal attempt; 7 cases $(13.72 \%)$ due to road traffic accident; 4 cases $(7.84 \%)$ due to bull gore injury; 1 case $(1.96 \%)$ due to accidental fall. Emergency tracheostomy was done in 16 cases (33.33\%). An average hospital stay for most of the patients was less than 3 weeks. 2 victims (3.92\%) died due to haemorhage, aspiration pnuemonia and septicemia. Conclusions: Our study found that the majority of the victims were males of age between 20 years to 40 years from poor socioeconomic status. Social commitment and political motivation, decrease in the poverty, individual awareness, increase in economic growth, and literacy rate will prevent the cut throat injuries. Early and improved management will reduce the mortality and morbidity.
\end{abstract}

\section{Keywords}

Cut Throat Injury, Treatment, Outcome

\footnotetext{
${ }^{*}$ Corresponding author.
}

How to cite this paper: Panchappa, S.A., Natarajan, D., Karuppasamy, T., Jeyabalan, A., Ramamoorthy, R.K., Thirani, S. and Swamirao, R.K. (2014) Cut Throat Injuries-A Retrospective Study at a Tertiary Referral Hospital. International Journal of Otolaryngology and Head \& Neck Surgery, 3, 323-329. http://dx.doi.org/10.4236/ijohns.2014.36058 


\section{Introduction}

Penetrating neck trauma involves a sharp object penetrating the skin and violating the platysma layer of the neck. This includes gunshot wounds, stab or puncture wounds, and impalement injuries. Penetrating neck injuries, like any trauma, may be classified as intentional or non intentional. It can also be classified as homicidal, accidental or suicidal. The objects causing these injuries can be divided into stabbing instruments (e.g., knives, cutting instruments, razors, blades, broken glass pieces, broken bottles, puncturing objects, impaling objects) and shooting instruments (e.g., missiles, projectiles). Wounding instruments have specific characteristics that affect surgical findings. For example, stab wounds typically have a $10 \%$ higher rate of negative exploration than injuries from projectiles. The object's mass and shape will determine the extent of a penetrating injury.

Globally, cut throat injuries account for approximately $5 \%$ to $10 \%$ of all traumatic injuries with multiple structures being injured in 30\% of patients. However, in developing countries the incidence is increasing at a fast rate partly because of increasing conflict over limited resources, poor socioeconomic status, poverty, unemployment, easy access to firearms, alcohol and substance misuse and increased crime rates [1]-[3].

According to Roon and Christensen's classification, neck injuries are divided into three anatomical zones.

Zone I is defined as the area from the clavicles to the inferior margin of cricoid cartilage. Structures within this zone include the vertebral and proximal carotid arteries, major thoracic vessels, superior mediastinum, lungs, esophagus, trachea, thoracic duct and spinal cord.

Zone II extends from the inferior margin of the cricoid cartilage to the angle of the mandible. The carotid and vertebral arteries, jugular veins, esophagus, trachea, larynx and spinal cord are found in this zone.

Zone III is located between the angle of the mandible and the base of the skull. It includes the carotid and vertebral arteries, pharynx and spinal cord [1].

The location of the injury suggests which structures may be involved. Injuries to the larynx and trachea can be asymptomatic or may cause hoarseness, laryngeal stridor, subcutaneous emphysema or dyspnea secondary to airway compression or aspiration of blood. Injury to the great vessels presents with visible external blood loss, neck hematoma, bruit, pulselessness, distal ischaemia, hypotension and in varying degrees of shock. Following the cut throat, hemorrhage, shock and asphyxia from aspirated blood are the commonest causes of death. Immediate measures will save lives in vast majority.

Cut throat injuries pose a great challenge because multiple vital organs for phonation, deglutition, vascular and neurological structures vulnerable to injuries are present in the small, confined unprotected area. Many of these are close to the skin and easily vulnerable to injury. Injuries to the neck can be both complex and challenging to treat them. The management of these injuries requires a multidisciplinary approach requiring the close association of the otolaryngologists, the vascular surgeons, the anesthetists and the psychiatrists [4].

\section{Aims and Objectives}

1) To study the socio demographic pattern of cut throat injuries at our hospital.

2) The most common causes for cut throat injury.

3) Site and depth of the injury.

4) Treatment received at our hospital and outcome.

\section{Methods and Materials}

The study was conducted at Government Rajaji Hospital, Madurai, India. Our hospital is the highest referral unit for south Tamilnadu province, India. This is a 2518 bedded hospital. On an average the total number of trauma cases per year is around 23,840. It encompasses a total population of twenty-five million. The study period was 18 months from Jan 2013 to Jun 2014. The type of study is a retrospective study.

A total of 51 cases of cut throat injury were included in the study irrespective of their age and sex who attended ENT department and also patients referred from general surgery and trauma departments. The data regarding the study population were collected from the trauma department and from the registers of operation theatres and complied in a proforma. The study population were selected by purposive sampling from those patients who were admitted to this hospital and matches the inclusion criteria. All the data pertinent to the patients kept confidential.

Data were categorized according to the socio demographic pattern of the patient, cause for the injury, site of the neck injury (according to the defined zone of the neck), type and extent of the injury, presentation at time of 
admission, delay in the hospital arrival and duration of the hospital stay, records of mortality, treatment and outcome. The Kuppusamy classification was opted to know the socio economic status. The Kuppusamy classification includes education, occupation and monthly family income. A score of 26 - 29 is upper, 16 - 25 is upper middle, 11 - 15 is middle, 5 - 10 is lower upper and $0-5$ is lower socioeconomic class. The accumulated data were compiled and analyzed by standard statistical method and then presented in the following Tables 1-9.

The evaluation of a patient with cut throat injury should start with advanced trauma life support (ATLS), which begins with a primary survey giving importance to airway, breathing, and circulation (ABC) [5]. After patients vitals are stable, they undergo a secondary survey which includes a complete history and a thorough physical examination. These steps help to identify the likely injury complex and to direct further treatment or diagnostic testing.

The patients with superficial cut injuries, their wound was closed in layers under aseptic precautions. For those patients who had their larynx or trachea or pharynx severed were taken to operation theatre for repair and reconstruction under tetanus toxoid and broad spectrum antibiotic coverage. In such cases emergency tracheastomy was done. Defect in the laryngeal cartilage was reconstructed by 3-0 prolene. The mucous membrane, muscles, thyroid gland and soft tissues were approximated by 3-0 vicryl. Skin was closed with 3-0 prolene.

Table 1. Sex distribution of the patients $(n=51)$.

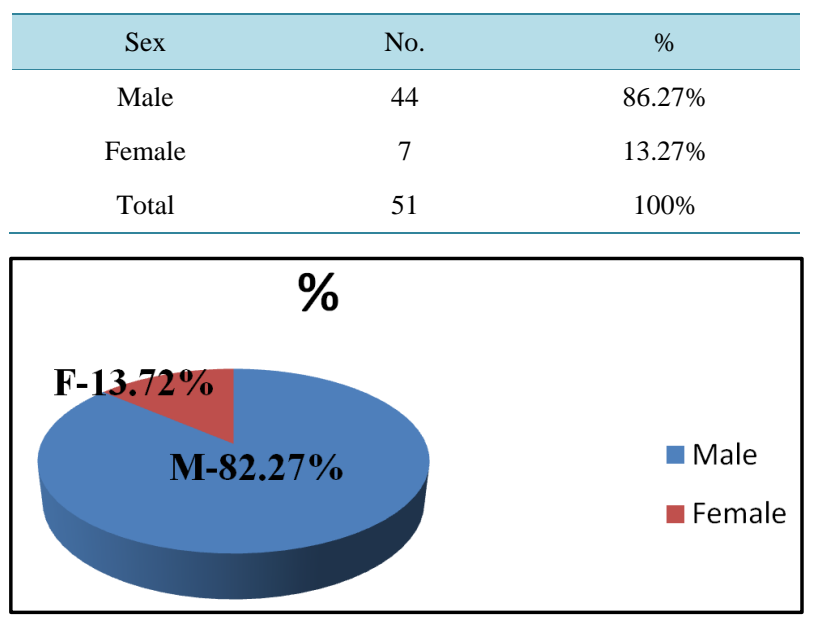

Table 2. Age distribution of the patients.

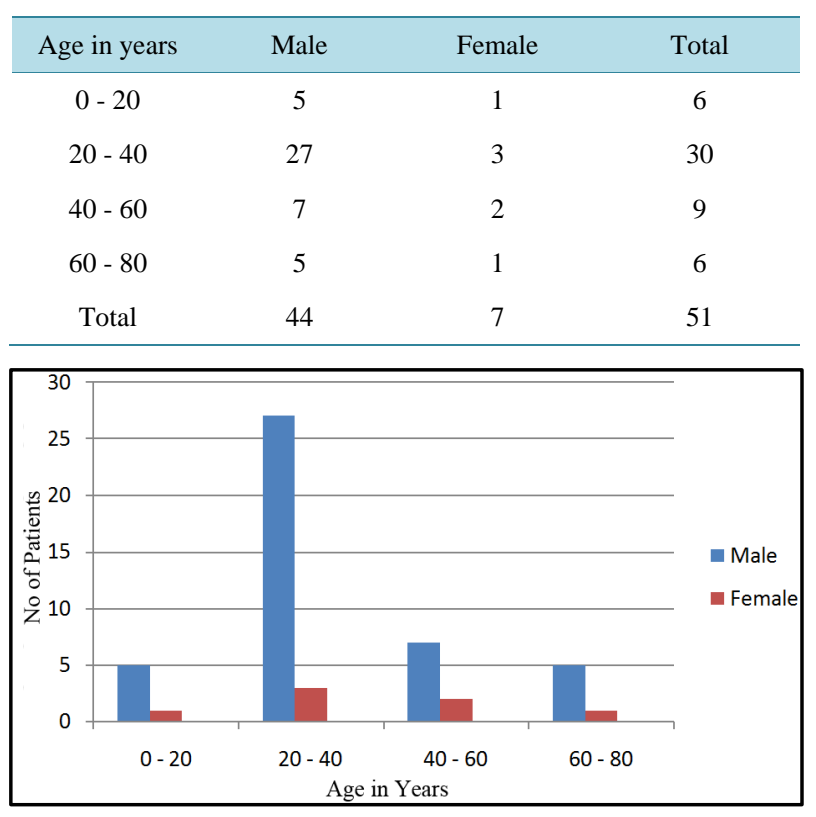


Table 3. Habitat of the patients.

\begin{tabular}{|ccc|}
\hline Habitat & No. & $\%$ \\
\hline Rural & 43 & $84.31 \%$ \\
Urban & 8 & $15.68 \%$ \\
Total & 51 & $100 \%$ \\
\hline Orban-15.68\% & \\
\hline & & \\
\hline & & \\
\hline & & \\
\hline & & \\
\hline
\end{tabular}

Table 4. Mode of injury of the cut throat patients.

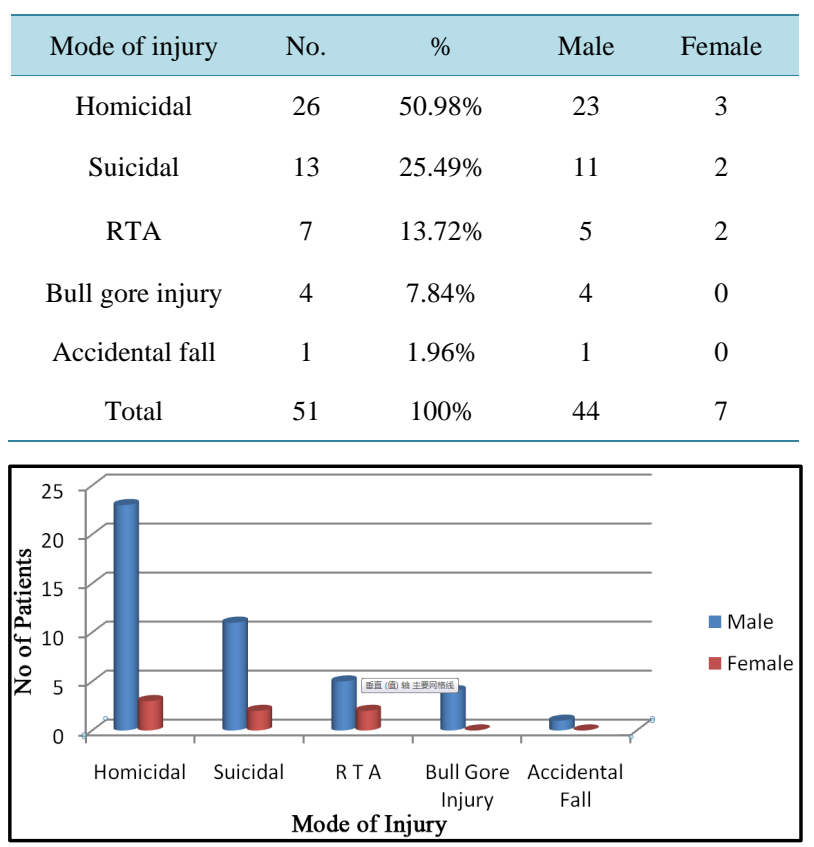

Table 5. Anatomical sites (zones) of injury of the patients.

\begin{tabular}{ccc}
\hline Anatomical sites (zones) & No. & $\%$ \\
\hline Zone I & 5 & $9.80 \%$ \\
Zone II & 32 & $62.74 \%$ \\
Zone III & 14 & $27.45 \%$ \\
Total & 51 & $100 \%$ \\
\hline
\end{tabular}


Table 6. Presentation of the cut throat patients.

\begin{tabular}{ccc}
\hline Presentation & No. & $\%$ \\
\hline Open wound \& bleeding & 19 & $37.25 \%$ \\
Respiratory distress & 16 & $31.37 \%$ \\
Inadequate wound management & 6 & $11.76 \%$ \\
Proper wound management & 6 & $11.76 \%$ \\
Severe cut injury in shock & 4 & $7.84 \%$ \\
Total & 51 & $100 \%$ \\
\hline
\end{tabular}

Table 7. Injury of structures of the neck.

\begin{tabular}{ccc}
\hline Injury of structures of the neck & No. & $\%$ \\
\hline Skin, soft tissue \& small vessels & 51 & $100 \%$ \\
Laryngeal injury & 12 & $23.52 \%$ \\
Hypopharynx & 4 & $7.84 \%$ \\
Throid \& thyroid vessels & 8 & $15.68 \%$ \\
Trachea & 1 & $1.96 \%$ \\
Carotid vessels & 2 & $3.92 \%$ \\
\hline
\end{tabular}

Table 8. Time of delay in hospital arrival of patients.

\begin{tabular}{ccc}
\hline Time of delay in hospital arrival & No. & $\%$ \\
\hline$<6$ hrs & 8 & $15.68 \%$ \\
$6-12$ hrs & 28 & $54.90 \%$ \\
$13-24$ hrs & 9 & $17.64 \%$ \\
$>24$ hrs & 6 & $11.76 \%$ \\
Total & 51 & $100 \%$ \\
\hline
\end{tabular}

Table 9. Treatment provided for cut throat patients.

\begin{tabular}{ccc}
\hline Treatment provided for cut throat patients & No. & $\%$ \\
\hline Simple wound closure & 35 & $68.62 \%$ \\
Laryngeal repair & 12 & $23.52 \%$ \\
Laryngeal \& hypopharyngeal repair & 16 & $31.37 \%$ \\
Tracheostomy & 16 & $31.37 \%$ \\
Tracheal reconstruction & 1 & $1.96 \%$ \\
Blood transfusion & 5 & $9.80 \%$ \\
Psychiatric consultation & 13 & $25.49 \%$ \\
\hline
\end{tabular}

Ryles tube was placed for hypopharyngeal repair. On an average hospital stay was less than three weeks.

\section{Results and Analysis}

A total 51 cases of cut throat injury were included in the study, in that males were 44 (84.3\%), females were 7 (13.72\%). and one male child (1.96\%). Male to female ratio was 6.2:1. Age ranged from 4 years to 80 years (mean 25.2). Majority of the patients were young adults aged between 20 to 40 years. 43 (84.31\%) cases were 
from rural community. The most common cause of cut throat in our study was homicide (50.98\%), followed by suicidal (25.49\%), road traffic accident (13.72\%), bull gore injury (7.84\%) and accidental fall (1.96\%). According to the anatomical site, 32 (62.74\%) cases had injury in Zone II, 14 (27.45\%) cases in Zone III and 5 (9.80\%) cases in Zone I. 16 (31.37\%) cases had emergency tracheostomy.

Majority of the patients were referred to our hospital after primary resuscitation at other hospitals. The most common presentation was with open wound and bleeding \& 19 (37.25\%) cases presented with this finding. Cut throat injury with respiratory distress were $16(31.37 \%)$ cases. Referred patients with inadequate wound management at primary center were 6 cases $(11.76 \%) .6$ patients (11.76\%) were referred to our hospital with proper wound management and 4 cases (7.84\%) were with severe cut injury in shock.

Skin, soft tissue and small vessels were severed in all the cases (100\%). 12 cases (23.52\%) had laryngeal injury. Pharynx was injured in 4 cases (7.84\%). Thyroid and thyroid vessels were injured in 8 cases (15.68\%). Trachea was cut in one case (1.96\%). Carotid vessel injury observed in 2 cases (3.92\%). Study was done to know the time required to reach our hospital. Majority patients arrived in 6 hrs to 12 hrs following injury.

Treatment provided at our hospital was analyzed. Simple wound closure was done in 35 (68.62\%) cases. Laryngeal repair was done in 12 (23.52\%) cases. Laryngeal and hypopharyngeal repair done in 16 (31.37\%) cases. Tracheostomy was done in 16 (31.37\%) cases. Tracheal reconstruction done in 1 (1.96\%) case. Blood transfusion given for 5 (9.80\%) cases. Psychiatric consultation obtained for 13 (25.49\%) cases.

The hospital stay was on an average less than three weeks. Two patients died .The cause of death in one patient was hemorrhagic shock and second patient died on post operative day one due to cardiopulmonary arrest. Most common causes of morbidity were wound infection, change of voice, dysphagia, tracheal stenosis and permanent tracheostomy.

\section{Discussion}

Penetrating neck injury constitutes $5 \%$ to $10 \%$ of all the trauma cases. Amongst these, $30 \%$ patients have multiple injuries in other parts of the body. According to the world Health Organization (WHO), every year over 5 million people around the world die as a result of injury. As per WHO, it is estimated that for every death 10 20 gets hospitalized and 50 - 100 receives emergency care, indicating the burden on the resources of the country. Management of cut throat injury is a challenging task as the most important organs like larynx, trachea, pharynx, carotids and nerves are present in a small confined area. Cut throat injuries are less commonly reported in the literature.

In our study we included 51 cases of cut throat injury. Males to female ratio was (6.2:1). Cut throat injury was common in males, who came from rural area. Most of them were unemployed and of low education level. The age group ranged from 4 years to 80 years. Most of them were young between the age group 20 to 40 years. Our results were similar to other previous studies. Male preponderance in this age group is due to their active participation in risky behaviors and their frequent involvement in interpersonal conflicts. This has great economic setback since these are people who are the major bread winners for the family. Their most productive years are lost in the sufferings and the injuries impose a considerable burden on their families and the society as a whole.

The most common cause was found to be homicide followed by suicidal attempt, road traffic accidents, bull gore injury and accidental fall in our study. Males dominated both in homicidal and suicidal cut throat injury. Study conducted in the western population shows suicidal cut throat to be the most common cause, in contrast to our study. But in developing countries homicide is the most common cause for cut throat. Bull fight is common in this part of India. Winning over the bull, depicts matador's bravery. Bull horn injuries have not been regularly documented in the history. Wound depth is dependent on the force of penetration of the bull's horn into the matador's body. They are usually penetrating and contusive [6].

The majority of injuries in our study were in Zone II and most of them had laryngeal injury which is in keeping with other studies [3]. The predominance of Zone II injuries in our study is attributable to the fact that unlike Zones I and III, Zone II is not protected by bony structures making it more vulnerable to injuries. Injuries in this zone are the easiest to expose in cut throat injury. Iseh K.R. et al. suggested that pharyngeal, hypopharyngeal and laryngeal mucosal lacerations should ideally be repaired early (within 24 hours) [7]-[9].

Most of the patient reached the hospital within 6 to 12 hrs following injury. Outcome was better for the patients who received timely primary care and who managed to reach the hospital at the earliest. Patients who had laryngeal and pharyngeal injury had tracheostomy done for airway management. For most of them tracheostomy 
tube removal was done by 10 to 12 days. Psychiatric support was obtained in the patients who attempted suicide to prevent further such episodes.

\section{Conclusions}

Incidence of cut throat injuries and associated morbidities \& mortalities are not uncommon in present day life. The aim and objective of our study is to analyze the socio demographic pattern, causes or motives of the cut throat and its outcomes. The socio demographic data, motives of trauma, structures injured, treatment given at our hospital, complications and mortalities were analyzed. In conclusion according to our study homicide is the commonest cause of cut throat injury, in this part of India. Unemployed young adults of low socioeconomic class are mostly affected.

According to the results of our study it is supposed that the early appropriate measures could save lives in vast majority. Addressing the root causes of violence such as poverty, illiteracy, unemployment and substance abuse will reduce the incidence of cut throat injuries in our society. Providing the efficient emergency health care services for primary care and effective ambulance system for immediate transport of cut throat victims to hospital will decrease time delay in reaching the hospital. Stringent and appropriate measures by the government agencies for enforcement of law and order will reduce the burden of homicidal cut throat in near future [10] [11].

\section{References}

[1] Fagan, J.J. and Nicol, A.J. (2008) Neck Trauma. In: Gleeson, M., Ed., Scott-Brown’s Otorhinolaryngology, Head and Neck Surgery, 7th Edition, Great Britain, Hodder Arnold, 1768.

[2] Penden, M., McGee, K. and Sharma, G. (2002) The Injury Chart Book: A Graphical Overview of the Global Burden of Injuries. World Health Organization, Geneva.

[3] Bhattacharjee, N., Arefin, S.M., Mazumder, S.M. and Khan, M.K. (1997) Cut Throat Injury: Retrospective Study of 26 Cases. Bangladesh Medical Research Council Bulletin, 23, 87-90.

[4] Ladapo, A.A. (1979) Open Injuries of the Anterior Neck. Ghana Medical Journal, 18, 182-186.

[5] Rao, B.K., Singh, V.K., Ray, S. and Mehra, M. (2004) Airway Management in Trauma. Indian Journal of Critical Care Medicine, 8, 98-105.

[6] Lloyd, M.S. (2004) Matador versus Taurus: Bull Gore Injury. Annals of the Royal College of Surgeons of England, 86, 3-5. http://dx.doi.org/10.1308/003588404772614597

[7] Iseh, K.R. and Obembe, A. (2011) Anterior Neck Injuries Presenting as Cut Throat Emergencies in a Tertiary Health Institution in North Western Nigeria. Nigerian Medical Journal, 20, 475-478.

[8] Onotai, L.O. and Ibekwe, U. (2010) The Pattern of Cut Throat Injuries in the University of Port-Harcourt Teaching Hospital, Portharcourt. Nigerian Medical Journal, 19, 264-266.

[9] Kendall, J.L., Anglin, D. and Demetriades, D. (1998) Penetrating Neck Trauma. Emergency Medicine Clinics of North America, 16, 85-105. http://dx.doi.org/10.1016/S0733-8627(05)70350-3

[10] Aich, M., Alam, K., Talukder, D.C., Sarder, R., Fakir, A.Y. and Hossain, M. (2011) Cut Throat Injury: Review of 67 Cases. Bangladesh Journal of Otorhinolaryngology, 17, 5-13. http://dx.doi.org/10.3329/bjo.v17i1.7616

[11] Kundu, R.K., Adhikary, B. and Naskar, S. (2013) A Clinical Study of Management and Outcome of 60 Cut Throat Injuries. 
Scientific Research Publishing (SCIRP) is one of the largest Open Access journal publishers. It is currently publishing more than 200 open access, online, peer-reviewed journals covering a wide range of academic disciplines. SCIRP serves the worldwide academic communities and contributes to the progress and application of science with its publication.

Other selected journals from SCIRP are listed as below. Submit your manuscript to us via either submit@scirp.org or Online Submission Portal.
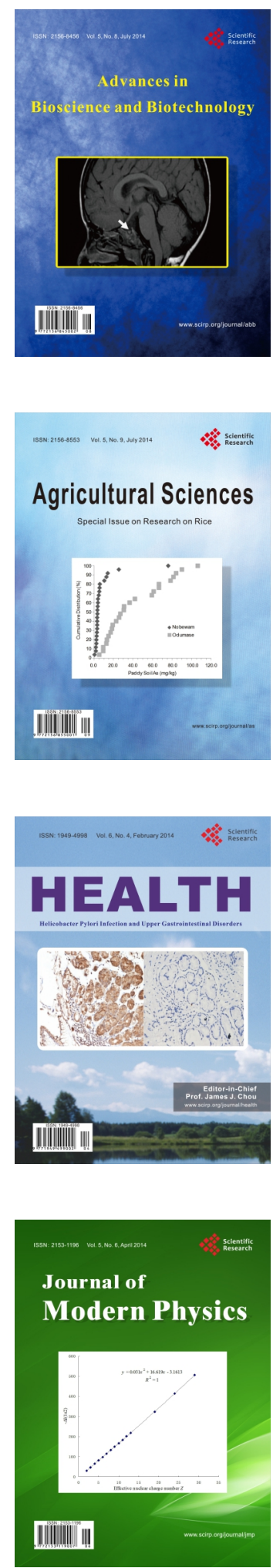
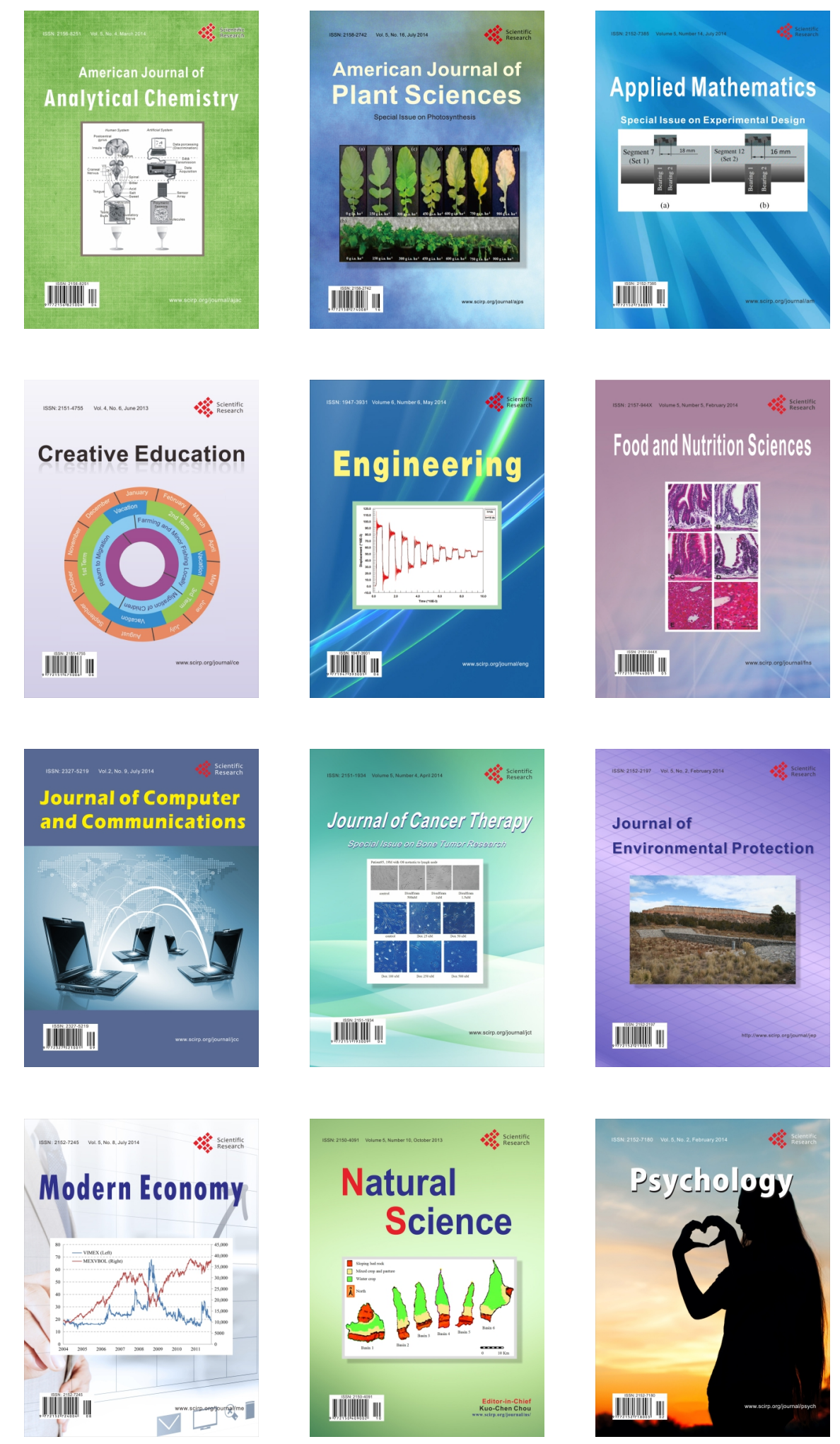